2. Rosado, M. J. In: Alternativas escassas: saúde, sexualidade e reprodução na América Latina. Fundação Carlos Chagas, Editora 34.1994.

3. Isambert, F.A. In: Contraception et avortement, dix ans de débat dans la presse (1965 - 1974). Paris, Editions du CNRS, 1979.

4. Papa Paulo VI. In: Sedoc. Petrópolis, Vozes, pp.1034-1036. 1973

5. Anjos, M. F. In: Da argumentação sobre a moralidade do aborto ao modo justo de se argumentar em teologia moral. SP, Loyola. 1976.

6. Papa Paulo VI. In: Sedoc. Petrópolis, Vozes, pp.833-839.1977.

7. CNBB. Ata no 10 da $22^{a}$ Assembleia Geral da CNBB (25.04-04.05.84) sobre a defesa da vida, Comunicado Mensal da CNBB, 1984.

8. CNBB. "A despenalização do aborto". Votação 7 da $31^{a}$ Assembleia Geral da CNBB, Comunicado Mensal da CNBB. 1993.

9. Separe, F.C.; Hamer, J. Apresentação da Declaração sobre o Aborto Provocado, Declaração da Sagrada Congregação para a Doutrina da Fé, Comunicado Mensal da CNBB. 1974.

10. Guillemain, B. In:Encyclopaedia Universalis, corpus 14, Paris, Encyclopaedia Universalis, pp.1185-1187.1985.

11. Cross, F.L.; Livingstone, E.A.In: The Oxford Dictionary of the Christian Church. Oxford University Press. 1997.

12. Melo, G. "Problemática religiosa de la mujer que aborta". Encuentro de investigadores sobre aborto inducido en América Latina Y el Caribe, Santafé de Bogotá, Universidad Externado de Colombia. 1994.

13. Hurst, J.; Muraro, R.M. In: Uma história não contada. Montevideo, Católicas por el Derecho a Decidir, pp.7-40.1992.

14. Wijwickrema, S. In: Seminar on socio-cultural aspects of population. 1996. Boletins Fêmea, Editado pelo Centro Feminista de Estudos e Assessoria (CFEMEA). Brasília - DF, no.55, agosto/97, no.56, setembro/97, no.57, outubro/1997.

15. Stefen, L. Abortion (A reader). The Pilgrim Library of Ethics. 1996.

16. P. Ladrière. In: Opression des femmes et religion. Colloque de I'Association Française de Sociologie Religiouse (1-2/12/80), Centre d'Études Sociologiques, CNRS, Travaux et Documents, Societé des Amis du Centre d'Études Sociologiques, Paris, 1980.

17. Ladrière, P. "Ética y poder religioso em el campo de la reproducción de la vida humana", in Selecciones de teologia, n.98, vol.25, abril-junho, p.119-128, 1986.

18. D. Callahan. In: Lloyd, Steffen. Abortion, a reader. The Pilgrim Press, pP.82-93. 1996.

19. McCormick, R.A. The critical calling. Reflections on moral dilemmas since Vatican II. Georgetown University Press. 1989.

20. Catecismo da Igreja Católica. Rio de Janeiro, Editora Vozes. 1993.

\section{ABORTO SECURO: UM DIREITO DAS MULHERES?}

\author{
Nilcéa Freire
}

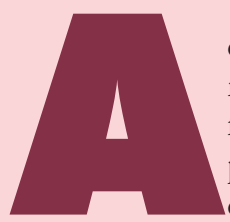

discussão sobre o aborto no país e a primazia das mulheres em tomarem a decisão sobre sua realização foi, desde sempre, revestida de grande simbolismo posto que confronta a sociedade com temas "intocáveis", como o início da vida humana e a "propriedade" sobre os corpos femininos.

Nos últimos anos e, especialmente a partir da I e da II Conferências $\mathrm{Na}$ cionais de Políticas para as Mulheres, o tratamento do tema ganhou novos contornos. A aprovação da resolução que demandava ao governo brasileiro iniciativas que viessem a rever, no sentido descriminalizante, a legislação brasileira, inseriu a questão do aborto no campo de discussão das políticas públicas, mais especificamente, no âmbito da saúde pública.

Por outro lado, vale registrar que no Brasil, seguindo uma tendência mundial, houve no mesmo período um acentuado crescimento e/ou explicitação de posições conservadoras quanto ao tema, por parte de diferentes grupamentos religiosos que ampliaram sua força política no Congresso Nacional.

Na sociedade brasileira, apesar da legislação restritiva e criminalizante, a prática clandestina do aborto ocorre em escala que coloca em risco a vida de milhares de mulheres, sobretudo nos extratos de renda mais baixos da população, configurando-se, desta maneira, como a quarta causa de morte materna no Brasil.

Estima-se que, em 2005 (1), para cada 100 nascidos vivos ocorreram 30 abortos realizados em condiçôes inseguras e precárias. Em termos de mortalidade materna, se aprofundarmos as estatísticas, considerando os aspectos socioeconômicos, verificamos que as maiores vítimas são mulheres negras e pobres. A desagregação dos dados em relação ao quesito raça e cor elucida parte da desigualdade étnico-social entre as brasileiras: das mortes maternas causadas pelo aborto em 2004, aproximadamente 9\% eram mulheres brancas e $20 \%$ eram negras (2).

Em 2009, foi apresentado um estudo financiado pelo Ministério da Saúde, "20 anos de pesquisa sobre o aborto no Brasil”, coordenado por Débora Diniz e Marilena Corrêa, em que se revela o perfil das mulheres que realizam o aborto no Brasil, concluindo-se que são, predominantemente, mulheres entre 20 e 29 anos, em união estável, com até oito anos de estudo, trabalhadoras e católicas. Os resultados da pesquisa põem por terra o estereótipo de que somente mulheres "irresponsáveis" e "inconsequentes" recorrem ao aborto como solução para o problema da gravidez indesejada e o reposiciona como opção, via de regra difícil, de mulheres e, porque não dizer, de homens, que por diferentes razões vivenciam essa contingência de vida.

Independentemente das condiçōes econômicas, sociais, de escolaridade, entre outras, em que se encontram essas mulheres, a criminalização da prática do aborto as iguala sonegando-lhes o direito à saúde e impondo-lhes as consequências no campo psíquico e social de uma gravidez não desejada.

As mulheres que recorrem ao aborto inseguro ou clandestino ficam expostas ao risco dos agravos a sua saúde e até a morte, além do 
sofrimento moral de um processo judicial que pode levar à condenação. O caso das dez mil mulheres de Mato Grosso do Sul é exemplar no sentido de demonstrar as possíveis consequências de uma legislação tão anacrônica quanto injusta.

Ao avaliar o VI Relatório Nacional Brasileiro, o Comitê de Eliminação da Discriminação contra Mulheres das Naçōes Unidas, recomendou, juntamente com outras medidas, que o país proceda à revisão da legislação, com vistas à descriminalização do aborto, e que prossiga com seus esforços para aumentar o acesso das mulheres à assistência à saúde, em particular aos serviços de saúde sexual e reprodutiva, o que inclui a assistência aos casos e às complicações decorrentes de abortos não seguros. Tal recomendação se fundamenta nos dados sobre morte materna em consequência de abortamento inseguro.

As recomendações do Comitê revalidam e reforçam os compromissos assumidos pelo país em diferentes instrumentos internacionais, por meio dos quais se reconhece que a exposição aos riscos de um abortamento inseguro implica em violação dos direitos humanos de meninas e mulheres, a exemplo da Declaração de Viena, de 1993, e que direitos sexuais e reprodutivos são direitos humanos, conforme a definição resultante da IV Conferência Mundial sobre a Mulher, em Pequim, em 1995. O compromisso do Estado brasileiro expresso nesses instrumentos é claro no sentido da abordagem do aborto como problema de saúde pública e da necessidade de rever a legislação restritiva e punitiva sobre o tema.

Urge, portanto, aprofundar o debate entre nós com a delicadeza que o assunto merece e com a consciência da polêmica que desperta. Sendo partícipe da Convenção sobre a Eliminação de todas as Formas de Discriminação contra a Mulher, o Estado brasileiro deve garantir os direitos sexuais e reprodutivos das mulheres brasileiras através da discussão livre e informada.

Para isso, é imprescindível superar os paradigmas estigmatizantes do machismo e do sexismo que obstaculizam a verdadeira promoção da igualdade entre homens e mulheres e avançar rumo a uma sociedade garantidora da totalidade dos direitos humanos.

Urge enfrentar o debate sobre o aborto com a consciência da proporção de seus impactos na vida das mulheres. E aqui, cabe lembrar o julgamento da Ação de Arguição de Descumprimento de Preceito Fundamental no 54 sobre a interrupção de gestações de fetos anencéfalos que, felizmente, teve parecer favorável do Supremo Tribunal Federal.

Ainda que delicada e difícil a discussão sobre o tema, o aborto está, mais do que nunca, em pauta e à sociedade brasileira, e em especial às mulheres, cabe decidir sobre qual devem ser os próximos passos.

Nilcéa Freireémédica e professora da Universidade Estadual do Rio de Janeiro (UERJ). Foi ministra da Secretaria Especial de Políticas para as Mulheres da Presidência da República (2004-2010).

\section{REFERÊNCIAS BIBLIOGRÁFICAS}

1. Adesse, L.; Monteiro, M.F.G.. In: Ipas Brasil. Disponível em: http://www. ipas.org.br/arquivos/factsh_mag.pdf (acesso em 2/2/10)

2. Ministério da Saúde. Secretaria de Gestão Estratégica e Participativa. Painel de Indicadores do SUS. Vol.1,2008. Disponível em: http://portal. saude.gov.br/portal/arquivos/pdf/painel_\%20indicadores_do_SUS. pdf (acesso em 2/2/10).

\section{ABORTO E OBJEÇÃO DE CONSCIÊNGIA}

\author{
Beatriz Galli \\ Jefferson Drezett \\ Mario Cavagna Neto
}

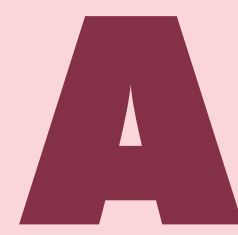

Conferência Internacional sobre População e Desenvolvimento (ICPD), realizada no Cairo, em 1994, e a 4a Conferência Internacional sobre a Mulher, em Beijing, em 1995, consolidam os direitos humanos das mulheres no campo da saúde sexual e reprodutiva (1). Em Beijing, os países participantes afirmaram o direito das mulheres de decidir livremente sobre fertilidade e sexualidade, livres de coerção, discriminação ou violência (2). No Cairo, os governos reconheceram o aborto como grave problema de saúde pública, comprometendo-se a reduzir a necessidade de recorrer ao aborto por meio da expansão do planejamento reprodutivo (1).

A Assembleia Geral das Nações Unidas, em 1999, aprovou a implementação do IPCD + 5, acrescentado que, nas circunstâncias em que o aborto não contraria a lei, governos devem adotar medidas que garantam que esses abortos sejam praticados de forma segura e acessível (3). A atenção ao tema do aborto nas conferências internacionais se justifica. A maior parte das mortes maternas e das graves sequelas do aborto pode ser prevenida com uso de tecnologia apropriada por profissionais de saúde preparados (4). Nos países com acesso a serviços seguros a probabilidade de morte por aborto é de $1 / 100.000$ procedimentos, contrastando com o risco de $1 / 100$ verificado nos países em desenvolvimento onde o aborto é proibido e realizado de forma clandestina e insegura (5).

O Brasil, signatário dessas conferências e de tratados internacionais de direitos humanos, assume compromisso com questóes relativas ao aborto (6). No entanto, sua prática ainda é crime tipificado no Código Penal, com exceção das situações previstas pelo artigo 128, que estabelece, desde 1940, que não é crime e não se pune o aborto em casos de gravidez decorrente de estupro ou quando há risco de morte para a gestante. Mais recentemente, consequência da incontestável evolução da propedêutica fetal, o poder judiciário passa a conceder autorização para interromper gestaçōes com anomalias fetais graves e incompatíveis com a vida extra-uterina (7). Nessas situações de exceção o aborto é inequívoco direito da mulher. Cabe, portanto, ao Estado garantir que a interrupção dessas gestaçôes seja realizada de maneira ética, humanizada e segura (8).

Ainda que a última década tenha sido marcada pela crescente implantação de serviços de saúde que realizam o aborto previsto pela lei e por políticas públicas que qualifiquem sua prática, ainda existem desafios para que a interrupção dessas gestações seja acessível e segura para todas as mulheres. Profissionais de saúde, em geral, e obstetras e ginecologistas, em particular, são muitas vezes ambivalentes com relação ao aborto, consequência do conflito entre valores 